\title{
The effects of storage duration, temperature and cultivar on the severity of garlic clove rot caused by Fusarium proliferatum
}

\author{
D. Palmero Llamas , L. Gálvez Patón , M. García Díaz , J. Gil Serna , S. Benito Sáez
}

A B S T R A C T
Diseases that affect garlic during storage can lead to severe economic losses for farmers worldwide. One
causal agent of clove rot is Fusarium proliferatum. Here, the progress of clove rot caused by F. proliferatum
and its dependence on different storage conditions and cultivar type were studied. The effect of temper-
ature on mycelial growth, conidial viability, and fungal survival during garlic commercial storage was
documented. Samples of 50 bulbs from a randomized field trial with three different clonal generations
for purple garlic (F3, F4 and F5) and the F4 clonal generation for white garlic were labeled and stored
for two months (short-term storage). In addition, another sample of the F5 clonal generation of purple
garlic was stored for 6 months after harvest (long-term storage). The presence of the pathogen and the
percentage of symptomatic cloves were evaluated. A notable difference in the rot severity index (RSI) of
different garlic varieties was observed. In all studied cases, clove rot increased with storage time at $20^{\circ} \mathrm{C}$,
and the white garlic variety had a higher index of rot severity after two months of storage. Additionally,
there were clear differences between the growth rates of $F$. proliferatum isolates.
Studies conducted on the temperature responses of the pathogen propagules showed that expo-
sure for at least 20 min at $50^{\circ} \mathrm{C}$ was highly effective in significantly reducing the viability of fungal
conidia.
Pathogenicity studies showed that the fungus is pathogenic in all commercial varieties. However, there
were significant differences in varietal susceptibility between Chinese and white garlic type cultivars
(81.84 $\pm 16.44 \%$ and $87.5 \pm 23.19 \%$ symptomatic cloves, respectively) and purple cultivars ( $49.06 \pm 13.42 \%$
symptomatic cloves).

\section{Introduction}

Garlic is among the oldest known horticultural crops and is grown worldwide. Annual world garlic production is 22.2 million tons. Spain has the highest production rate in the European Union and the ninth highest in the world, with approximately 154,000 tons per annum grown on 16,000 ha (FAO, 2010).

Diseases that affect garlic can lead to major economic losses for farmers. In 2010, garlic bulb rot caused by Fusarium proliferatum (Matsushima) Nirenberg was detected for the first time in Spain (Basallote et al., 2011; García et al., 2011; Palmero et al., 2010a, 2011a,b). Symptomatic cloves showed internal tan-colored rot progressing toward the clove apex, with occasional white mycelia in rotted cavities.
Previous studies demonstrated that $F$. proliferatum can also affect other Allium spp. (Dissanayake et al., 2009; García et al., 2011; Stepien et al., 2011). Moreover, the presence of $F$. proliferatum has been reported in garlic in other countries (Dugan et al., 2007; Ravi and Prasand, 2012) as well as its ability to produce fumonisin in garlic in Germany (Seefelder et al, 2002). Moreover, F. proliferatum produces a number of toxins apart from fumonisins, such as moniliformin (Marasas et al., 1984), beauvericin (Logrieco et al., 1998; Plattner and Nelson, 1994), fusaric acid (FA) (Bacon et al., 1996) and fusaroproliferin (Ritieni et al., 1995). Because fresh garlic is consumed broadly in many countries, the production of mycotoxins in cloves infected with $F$. proliferatum must not be disregarded (Palmero et al., 2010b; Stankovic et al., 2007; Stepien et al., 2011).

Miscellaneous fungicide trials generally failed to demonstrate any effects on F. proliferatum (Dugan et al., 2007). In experiments using superficially wounded bulbs, only benomyl gave positive results (Dugan et al., 2007). This fungicide is currently forbidden in the EU, and alternative fungicides did not provide satisfactory field 
control. Therefore, it is necessary to explore other control measures for the pathogen. One alternative to the use of fungicides in the field is to use tissue culture to obtain germplasm that is free of fungi and viruses; this technique is currently routinely used by many garlic producers in Spain. We have carried out sampling to check the effectiveness of meristem cultivation as a control measure to eradicate $F$. proliferatum inoculum from the cloves and found that seedlings produced via tissue culture were free of $F$. proliferatum infection. Successive crop cycles are needed to reach the F3, F4 and F5 clonal generation (garlic marketed to farmers as seed). Garlic is an apomictic species whose "seeds" are the cloves of the previous generation. Thus, the inoculum may accumulate in the cloves used for the following season. Bioassays on field soil demonstrated that soil cropped to garlic was infected with $F$. proliferatum (Dugan, 2007; Palmero et al., 2011a,b). Healthy cloves coming from tissue cultures may become infected if they are planted in soil in which the pathogen is present. It is known that the fungus can survive prolonged freezing temperatures, although it does not produce chlamydospores (Leslie and Summerell, 2006; Nelson et al., 1983), and it may even remain viable in wheat seeds stored at $-18^{\circ} \mathrm{C}$ after 30 years of storage (unpublished data). When cloves are not visibly symptomatic, it is very difficult to select against them for the following cycle. Because the scales of the cloves cover emerging symptoms, diseased bulbs cannot be completely removed, and the disinfection of planting stock was not always satisfactory.

Another alternative of control is thermotherapy (hot water treatment), which has been used against fungal, nematode and mite pests in garlic. The temperature of treatment varies widely depending on the cultivar. Previous studies with the garlic varieties cultivated in Spain set the temperature at $50^{\circ} \mathrm{C}$ (Vares et al., 2009 ), but the effect of this temperature on $F$. proliferatum is currently unknown. Furthermore, little is known about the progress of infected tissue of bulbs during the storage period.

This work aims to study the progress of clove rot depending on the temperature and the type of variety stored. Once we identified the causal agent and confirmed its pathogenicity, we aimed to study the effect of temperature on mycelial growth and on conidial viability during commercial garlic storage.

\section{Materials and methods}

\subsection{Storage treatments}

A field trial was carried out in the experimental field of Coopaman SCL. Naturally infected garlic plants were randomized in the field trial $(100 \mathrm{~m} \times 2.75 \mathrm{~m}$ elemental plot) with two replicates (plant density 20 plants $/ \mathrm{m}^{2}$ ) for each of the two varieties tested: cv. Morado de Cuenca (purple garlic) and cv. Vigor supreme (white garlic). Samples of both varieties were routinely dried and cleaned. The effect of short-term storage on the rot progress of garlic bulbs was studied in three different generations for purple garlic (F3, F4 and F5) and in the F4 generation for white garlic. To analyze the different storage conditions, samples of 150 harvested bulbs of each of the studied clonal generations were labeled, and subsamples of 50 bulbs were evaluated at the initial point and at one-month intervals thereafter (short-term storage). In addition, another sample of 50 bulbs of the F5 clonal generation of purple garlic (the main cultivar in the area) was stored in climatic chamber at $5^{\circ} \mathrm{C}$ for 6 months after harvest (long-term storage).

The incidence of the pathogen and the percentage of symptomatic cloves were evaluated in this subsample of 50 bulbs from F5 samples. For each subsample, each of the 50 bulbs was individually covered with aluminum foil and stored in climatic chambers at $20^{\circ} \mathrm{C}$ or $5^{\circ} \mathrm{C}$. All tests were repeated. Disease symptoms were rated for every clove within every bulb (as described below) every month in the short-term storage test and every three months in the long-term storage test. Subsamples of 50 bulbs within each treatment were broken into component cloves, and the clove rot disease symptoms were graded into four classes: $\mathrm{N} 1=$ no symptoms; $\mathrm{N} 2=$ rotted spots; $\mathrm{N} 3=10-50 \%$ rotted clove; $\mathrm{N} 4$ = completely rotted clove. The rot severity index (RSI) was calculated with the following formula:

$\mathrm{RSI}=\frac{(\mathrm{N} 1 \times 0)+(\mathrm{N} 2 \times 1)+(\mathrm{N} 3 \times 2)+(\mathrm{N} 4 \times 3)}{\text { number of total cloves }}$

\subsection{Morphological and molecular identification of isolates}

Fifty bulbs from each sample and temperature tested were evaluated. Symptomatic bulbs were surface sterilized for $2-3 \mathrm{~min}$ in $0.5 \% \mathrm{NaOCl}$ in distilled water and rinsed in 4 changes of sterile distilled water, and pieces excised from the lesion margins were transferred to potato dextrose agar (PDA) or Komada's medium (Komada, 1975). Cultures were incubated at $25^{\circ} \mathrm{C}$ in the dark. Five to seven days later, Fusarium colonies emerging from the infected tissues were recognized morphologically as Fusarium, and representative isolates were assigned to species by the taxonomic criteria of Nelson et al. (1983), Gerlach and Nirenberg (1982) and Leslie and Summerell (2006). Eleven isolates were then subcultured in PDA using a single spore technique (Leslie and Summerell, 2006). For DNA extraction, three mycelial disks were excised from the margin of a 3- to 5-day-old PDA plate culture and crushed against the wall of a $1.5-\mathrm{mL}$ Eppendorf tube using a sterile pipette tip. DNA extraction was then carried out as described previously (Querol et al., 1992). A previously described speciesspecific PCR protocol (Jurado et al., 2006) was used to confirm the identification of the isolates using the primer set Fp3-F/Fp4-R (5'CGGCCACCAGAGGATGTG-3' $/ 5^{\prime}$-AACACGAATCGCTTCCTGAC-3').

\subsection{Confirmation of pathogenicity}

Pathogenicity was confirmed in eleven isolates of Fusarium recovered from different stored garlic samples using the methods published by Dugan et al. (2007), with minor modifications (Palmero et al, 2010b). Each isolate was inoculated into 3 cloves of the cultivar Morado de Cuenca. Prior to treatment, cloves were surface sterilized in $0.5 \% \mathrm{NaOCl}$ for $45 \mathrm{~s}$, rinsed in 4 changes of sterile water, and wounded to a depth of $4.5 \mathrm{~mm}$ with a sterile blade. The wound was inoculated with PDA colonized by the appropriate Fusarium isolate. A set of cloves was inoculated with sterile PDA as controls. Well-separated cloves were incubated in sealed, plastic boxes in a growth chamber at $25^{\circ} \mathrm{C}$ for 5 weeks and observed for clove rot symptom development.

\subsection{The effect of temperature on mycelial growth}

An in vitro evaluation of the effect of temperature on the radial mycelial growth of eleven isolates of $F$. proliferatum was also performed. Each of the isolates originally grown on selective Komada's medium (1971) was subcultured on PDA. To examine mycelial growth at various temperatures, $1-\mathrm{cm}$ diameter agar plugs were excised from the margins of two-week-old PDA cultures and aseptically transferred to the surface of fresh PDA medium.

Cultures were incubated at $5^{\circ} \mathrm{C}, 15^{\circ} \mathrm{C}, 25^{\circ} \mathrm{C}, 35^{\circ} \mathrm{C}$ and $40^{\circ} \mathrm{C}$ in complete darkness and examined after 2, 3, 6 and 9 days under a dissecting microscope. Colony margins were marked with permanent ink on the reverse side of the Petri dishes. For each colony, the mean radial mycelial growth was calculated by measuring two different colony radii in each of five plates per combination of isolate and temperature. The growth was corrected by subtracting the $1 \mathrm{~cm}$ diameter of the original inoculum plug. 


\subsection{The effect of high temperature on conidial viability}

Conidial suspensions of eleven $F$. proliferatum isolates were used to evaluate the effect of high temperature water treatment on the fungal viability of conidia. Agar plugs of 3-cm diameter were excised from the margins of two-week-old PDA cultures and aseptically transferred to $250 \mathrm{~mL}$ Erlenmeyer flasks (two replicates) containing liquid potato dextrose medium. Liquid cultures were incubated at $25^{\circ} \mathrm{C}$ in a rotatory incubator $(160 \mathrm{rpm})$ in complete darkness. After 3 days, the PD medium was filtered through double cheesecloth to remove the hyphae. All suspensions were initially evaluated in a hematocytometer to determine the initial conidial concentration. Suspensions were subjected to $50^{\circ} \mathrm{C}$ for periods of $1 \mathrm{~min}$ (thermal shock), 20, 40, 60 and $120 \mathrm{~min}$. Then, a $1 \mathrm{~mL}$ subsample was plated on a Petri dish containing PDA and incubated at $25^{\circ} \mathrm{C}$. Finally, the number of viable colonies in 5 replicates per combination of isolate and temperature were recorded after 5 days.

\subsection{The effect of cultivar on disease severity}

A panel of 17 garlic cultivars belonging to four different garlic types was tested against garlic rot caused by $F$. proliferatum. The varieties were provided by the Technical Unit of Plant Variety Evaluation of the Spanish National Institute of Agricultural Research (Fig. 3). F. proliferatum isolate A3a1, which was previously used for pathogenicity assays on related Allium spp. (García et al., 2011), was used for this test.

The isolate was subcultured from Petri plates into a $250 \mathrm{~mL}$ Erlenmeyer flask with liquid potato dextrose medium and incubated at $25^{\circ} \mathrm{C}$. Inoculum suspensions were prepared from liquid cultures ( 2 weeks old) and filtered thorough cheesecloth. The resulting suspensions were vigorously homogenized for $15 \mathrm{~s}$ with a vortex mixer. The inoculum size was adjusted to approximately $1.0 \times 10^{7}$ conidia/mL by microscopic enumeration with a cellcounting hematocytometer. The tips of each clove were excised, and $20 \mu \mathrm{L}$ of inoculum was transferred to each tested clove. Three replicates of five cloves each were tested for each variety, and controls with sterile water were included. The inoculated garlic cloves were incubated at $25^{\circ} \mathrm{C}$. After three weeks, clove rot was evaluated by counting the number of symptomatic cloves and by calculating the average quotient between the advancement of the rot and the total length of the inoculated clove using a digital scalimeter.

\subsection{Statistical analysis}

Analysis of variance (ANOVA) was performed using Statgraphics Centurion XV.II (Statistical 195 Graphics Corp., Herndon, VA).

\section{Results}

\subsection{The effects of storage duration on bulb rot.}

In all cases, clove rot increased with storage time at $20^{\circ} \mathrm{C}$. F5 showed the highest rot severity index (RSI) after two months for the three clonal generations tested within purple garlic (Table 1). The F4 white garlic variety had higher index of rot severity than the purple garlic variety for the same generation after two months of storage $(P=0.000)$. These results indicate that the RSI is strongly affected by the cultivar used.

In the long-term storage test, the RSI obtained in December 2010 (RSI $=0.3 \pm 0.28$ ) was high, but rot severity remained constant throughout the storage period thereafter. There were no significant differences $(P<0.05)$ between the values obtained in December 2010 and the values obtained in March 2011 (RSI =0.2 \pm 0.13 ) and June 2011 (RSI $=0.28 \pm 0.23$ ).

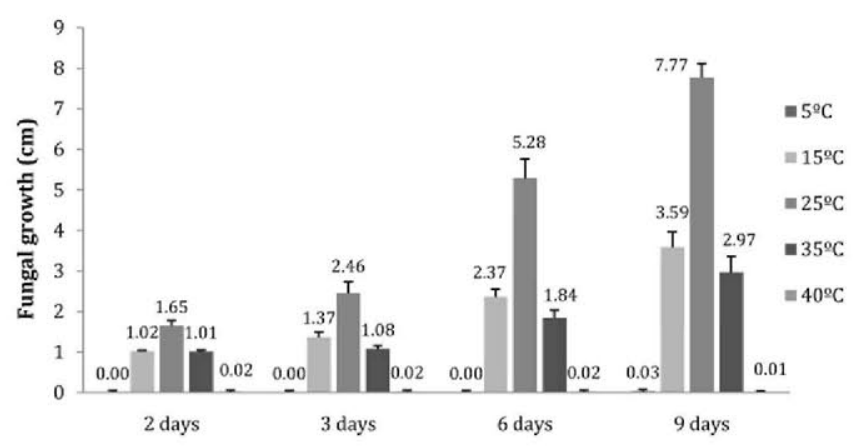

Fig. 1. The effect of temperature on fungal growth of $F$. proliferatum. The results are presented as the mean colony diameter of all eleven isolates tested, measured after nine days of incubation. Thin bars represent the standard deviations.

All analyzed symptomatic bulbs produced cultures characteristic of Fusarium with catenate microconidia borne on polyphialides, plus curved, usually 3- to 5-septate, macroconidia. Catenate microconidia were club shaped with a flattened base, aseptate, and were produced on mono- and polyphialides. Isolates were morphologically identified as F. proliferatum (T. Matsushima) Nirenberg (Nirenberg and O`Donnell, 1998).

All DNAs tested with the species-specific PCR assays produced an amplicon of the expected size, confirming the morphological identification of all 11 isolates as F. proliferatum.

Pathogenicity confirmation tests were positive for all the isolates used, and clove rot was induced in all cloves inoculated. Moreover, $F$. proliferatum was successfully re-isolated onto PDA from the symptomatic cloves. Each inoculated clove displayed symptoms typical of the bulb rot originally observed in the cultivated garlic. An internal tan-colored rot progressed from the inoculation site toward the clove apex, with white mycelium occasionally observed in the rot cavity. These symptoms matched those previously observed in Spanish garlic production areas. No fungi were isolated from control cloves, and the control cloves displayed no symptoms. Tissue excised from symptomatic cloves and plated on agar produced $F$. proliferatum isolates. The fungus could not be grown from controls.

\subsection{The effect of temperature on mycelial growth and conidial viability}

The effects of temperature on fungal growth and fungal viability during the drying process $\left(30^{\circ} \mathrm{C}\right)$, refrigerated storage $\left(5^{\circ} \mathrm{C}\right)$ and during normal storage conditions $\left(15-25^{\circ} \mathrm{C}\right)$ are shown in Fig. 1.

The growth diameter of the fungus differed with temperature. Minimal growth was observed after 9 days at 5 and $40^{\circ} \mathrm{C}$ $(0.03 \pm 0.04 \mathrm{~mm}$ and $0.008 \pm 0.02 \mathrm{~mm}$, respectively). Maximum growth was observed at $25^{\circ} \mathrm{C}(7.77 \pm 0.33 \mathrm{~mm})$ and was retarded at $15^{\circ} \mathrm{C}(3.54 \pm 0.34 \mathrm{~mm})$ and at $35^{\circ} \mathrm{C}(2.97 \pm 0.38 \mathrm{~mm})$ (Fig. 1). The study of the effect of temperature on mycelial growth confirmed the results of storage duration tests at $20^{\circ} \mathrm{C}$. Temperatures from approximately $20-25^{\circ} \mathrm{C}$ caused the greatest fungal growth, while higher or lower temperatures $\left(15\right.$ and $\left.35^{\circ} \mathrm{C}\right)$ slowed growth.

Fungal growth was almost zero at 5 and $40^{\circ} \mathrm{C}$. Previous studies indicated that $F$. proliferatum is able to withstand temperatures below $-10^{\circ} \mathrm{C}$ for at least 30 years (unpublished data), suggesting that temperatures above $40^{\circ} \mathrm{C}$ may show a thermotherapeutic effect applicable to garlic harvest.

In contrast, in vitro temperature dependence studies conducted on the pathogen propagules (Fig. 2) showed that exposure for at least $20 \mathrm{~min}$ at temperatures over $50^{\circ} \mathrm{C}$ is highly effective in significantly reducing conidial viability $(2.13 \%$ conidial viability compared with control assays). 
Table 1

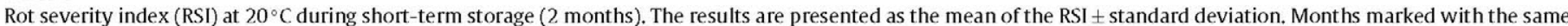
letter are not statistically significantly different.

\begin{tabular}{|c|c|c|c|c|}
\hline & \multicolumn{3}{|l|}{ Purple garlic } & \multirow{2}{*}{$\begin{array}{l}\text { White garlic } \\
\text { F4 generation }\end{array}$} \\
\hline & F3 generation & F4 generation & F5 generation & \\
\hline September 2010 & $0.14 \pm 0.04 \mathrm{a}$ & $0.00 \pm 0.00 \mathrm{a}$ & $0.03 \pm 0.04 a$ & $1.05 \pm 0.17 \mathrm{a}$ \\
\hline October 2010 & $0.56 \pm 0.37 b$ & $0.17 \pm 0.14 b$ & $0.53 \pm 0.25 b$ & $1.17 \pm 0.39 a$ \\
\hline November 2010 & $0.42 \pm 0.25 b$ & $0.15 \pm 0.12 b$ & $0.56 \pm 0.27 \mathrm{~b}$ & $1.49 \pm 0.58 \mathrm{a}$ \\
\hline Significance & · & $*$ & $\cdot$ & NS \\
\hline
\end{tabular}

* $P$ value $\leq 0.05$

"P value $\leq 0.01$

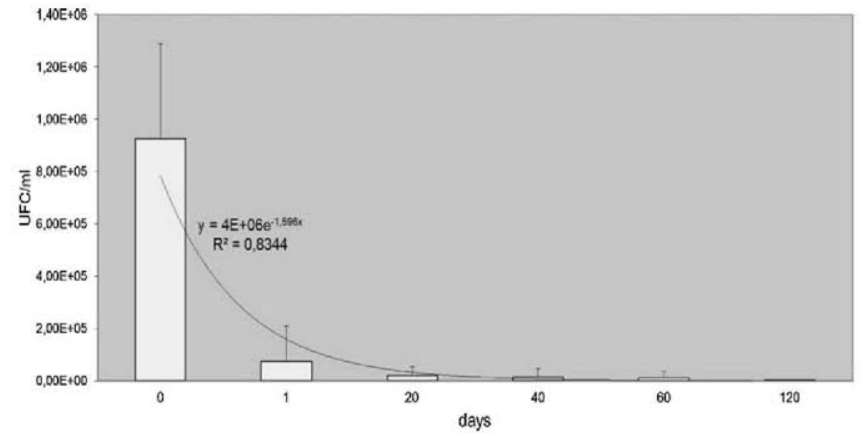

Fig. 2. The effect of time of exposure to $50^{\circ} \mathrm{C}$ water treatment on conidial viability. The figure shows the number of colony forming units (CFU)/mL after different times of incubation.

There was maximal effect on culture viability at $50^{\circ} \mathrm{C}$ in the first minute of thermal treatment, with an acute decrease in conidial viability (91.93\%) after 1 min of exposition (Fig. 2). This decline is accelerated with increasing exposure time. Only $0.0049 \%$ of conidia remained viable after $120 \mathrm{~min}$.

\subsection{The effect of cultivar on disease severity}

F. proliferatum was pathogenic in all 17 commercial varieties tested (Fig. 3). Furthermore, it was confirmed that there is a greater
Table 2

Symptomatic cloves (\%) and average quotient of the advancement of the rot over the total length of the inoculated clove on garlic (A. sativum) following artificial inoculation with isolates of $F$. proliferatum. Groups marked with the same letter are not statistically significantly different.

\begin{tabular}{lll}
\hline Cultivar type & Symptomatic cloves (\%) & Rot/clove ratio (\%) \\
\hline Purple & $49.06 \pm 13.42 \mathrm{a}$ & $43.21 \pm 37.91 \mathrm{a}$ \\
Tropical & $60.23 \pm 1.65 \mathrm{ab}$ & $58.14 \pm 12.61 \mathrm{ab}$ \\
White & $81.84 \pm 16.44 \mathrm{~b}$ & $80.80 \pm 29.04 \mathrm{~b}$ \\
Chinese & $87.50 \pm 23.19 \mathrm{~b}$ & $93.97 \pm 12.54 \mathrm{~b}$ \\
Significance & $\ldots$ & $\ldots$ \\
\hline
\end{tabular}

"Pvalue $\leq 0.01$

"** P value $<0.001$

degree of varietal susceptibility in White and Chinese type cultivars $(81.84 \pm 16.44 \%$ and $87.5 \pm 23.19 \%$ symptomatic cloves, respectively) versus purple cultivars ( $49.06 \pm 13.42 \%$ symptomatic cloves) (Table 2). Moreover, our experimental results showed higher average quotients for the advancement of the rot and the total length of the inoculated clove in white and Chinese garlic $(80.8 \pm 28.61 \%$ and $96.0 \pm 13.92)$ than for purple garlic $(43.21 \pm 40.41 \%)$ (Table 2$)$.

\section{Discussion}

Garlic bulbs are routinely stored by local producers at room temperature $\left(20^{\circ} \mathrm{C}\right)$ for two months (from September to November), but some garlic cooperatives use refrigerated chambers for

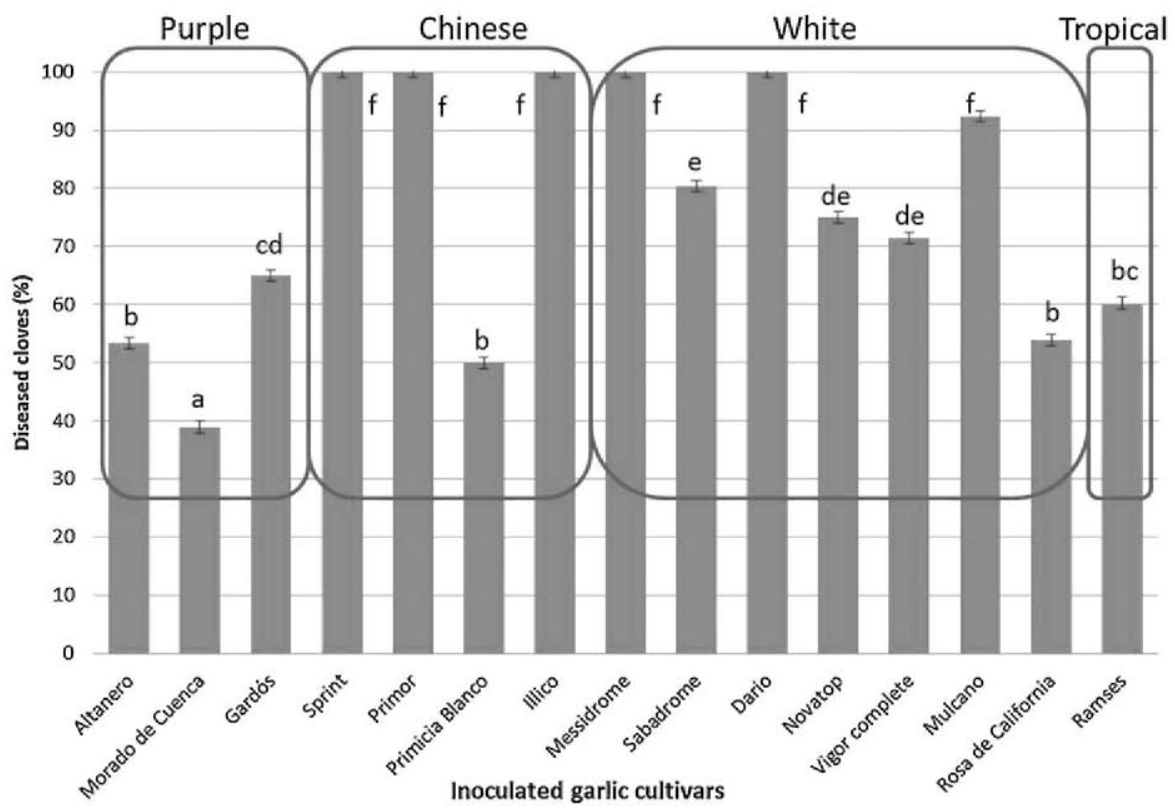

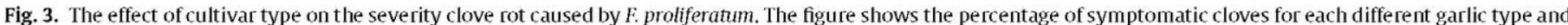

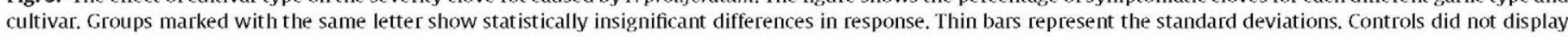
any symptoms. 
long-term trading $\left(5^{\circ} \mathrm{C}\right)$. Our experimental results show how different storage systems greatly influence rot progression and severity during the storage period. Therefore, batches held at $20^{\circ} \mathrm{C}$ for shortterm trading showed high rot rates, while samples stored at $5^{\circ} \mathrm{C}$ maintained low levels of rot, even when stored for much longer periods of time. In all cases, the use of morphological and molecular identification tools confirmed the fungal origin of the disease, proving Koch's postulates for F. proliferatum.

It is worth noting the difference in the response of the rot severity index (RSI) of garlic varieties. These differences were particularly striking at the initial stages; the initial RSI is much lower in purple garlic than in white garlic, which might suggest a certain varietal susceptibility.

After detecting the presence of fungus in stored bulbs and their behavior during the storage period, it was necessary to study temperature effect on fungal propagules to evaluate the changes in garlic bulbs over storage time. In this manner, we were able to extend existing information on pathogen epidemiology.

The results are consistent with those presented above in the storage conditions analysis, as well as the feedback received from farmers. Although the fungus did not grow at $40^{\circ} \mathrm{C}$, it remained viable, but it was expected that high temperatures over $40^{\circ} \mathrm{C}$ should affect the propagule viability of the pathogen.

Vares et al. (2009) reported a thermotherapy treatment in garlic appropriate for the control of other diseases. This work showed that there was a clear decrease in the mean of viable $F$. proliferatum $\mathrm{CFU} / \mathrm{mL}$ number in all isolates with increasing time of conidia exposure to the temperature studied $\left(50^{\circ} \mathrm{C}\right)$.

Moreover, pathogenicity studies indicated that rot progress is slower in purple varieties. These results are consistent with the observations made by farmers in the field, who report that white varieties are much more susceptible to the bulb rot than purple varieties. However, absolute resistance to the pathogen was not detected in the analyzed purple garlic germplasm (Fig. 3).

Therefore, to effectively control this disease, it is essential to use an integrated crop control strategy that involves not only the use of plant protection products and irrigation management or rotations but also an appropriate plant material choice and postharvest storage conditions for the harvested product.

\section{Conclusion}

The garlic growing season in Spain is very similar to that in the rest of the European Union. Garlic grows during the last months of the year (October and November) and it is harvested from June to late July or even August, depending on the variety. After the harvest, garlic is stored in farmers' warehouses at temperatures of approximately $20^{\circ} \mathrm{C}$ to be used as seeds (F3 or F4) in the following season or for an early commercialization (F5 generation); alternatively, it is taken to refrigerated chambers (usually cooperatives) for long-term storage at $4-5^{\circ} \mathrm{C}$ for subsequent marketing (F5 generation).

There was no fungal death at any of the temperatures studied. After the end of the study period, the plates were placed at $25^{\circ} \mathrm{C}$, and all fungi that did not grow at $40^{\circ} \mathrm{C}$ after nine days demonstrated their continued viability. In practice, if garlic is stored in a refrigerated chamber $\left(5^{\circ} \mathrm{C}\right)$ it stops the rot but the fungus does not die, and it resumes its activity when it is removed from the refrigerated storage chamber and put on the market.

Previous studies showed that a temperature of $50^{\circ} \mathrm{C}$ was the most appropriate for bulb treatment against fungal diseases and nematodes. In vitro assays using $50^{\circ} \mathrm{C}$ as thermotherapeutic temperature demonstrated a decrease in the conidial viability of $F$. proliferatum from the moment of exposure. However, the practical application these results to daily agricultural life is not simple; the fungus would be protected by external scales, and part of its mycelium would be already installed in early lesions of garlic cloves reserved for planting, so the effectiveness of thermotherapy could be reduced. Our working group has spent some time performing studies to address disease control in the field. It is advisable to use a pathogen-free plant material obtained by in vitro culture or by thermotherapy.

The results obtained in the present work provided novel information about the epidemiological aspects of $F$. proliferatum isolated from stored garlic. Moreover, the use different cultivars of enabled the detection of differential varietal responses to the pathogen. All varieties tested were susceptible to $F$. proliferatum, but there was some variation in response to inoculation, which could be exploited for cultivation in areas where the pathogen is established.

\section{Acknowledgement}

This research was partially funded by a Research Project P110255-389 (Technical University of Madrid - Coopaman SCL).

\section{References}

Bacon, C.W., Porte, J.K., Norred, W.P., Leslie, J.F., 1996. Production of fusaric acid by Fusarium species. Appl. Environ. Microbiol. 62, 4039-4043.

Basallote, M.J., Zurera, C., Melero, J.M., Prados, A.M., 2011. Nueva enfermedad en el cultivo del ajo ocasionada por Fusarium spp. Phytoma España 229, 55-58.

Dissanayake, M.L.M.C., Tanaka, S., Ito, S., 2009. Fumonisin B1 production by Fusarium proliferatum strains isolated from Allium fistulosum plants and seeds in Japan. Lett. Appl. Microbiol. 48, 598-604.

Dugan, F.M., Hellier, B.C., Lupien, S.L., 2007. Pathogenic fungi in garlic seed cloves from the United States and China, and efficacy of fungicides against pathogens in garlic germplasm in Washington State. J. Phytopathol. 155, 437-445.

FAO (Food, Agriculture Organization of the United Nations), 2010. FAOSTAT Production Statistics. FAO, Rome, Italy.

García, M., de Cara, M., Gălvez, L., Iglesias, C., Vares, L., Tello, J.C., Palmero, D., 2011. Especificidad parasitaria de aislados de Fusarium proliferatum (Matsushima) Nirenberg sobre especies del gênero Allium. Bol. San. Veg. Plagas 37, 195206.

Gerlach, W.L., Nirenberg, H., 1982. The genus Fusarium. A pictorial atlas. Mitt. Biol. Bundesanst. 209, 1-406.

Jurado, M., Vázquez, C., Marín, S., Sanchis, V., González Jaên, M.T., 2006. PCR-based strategy to detect contamination with mycotoxigenic Fusarium species in maize. Syst. Appl. Mic robiol. 29, 681-689.

Komada, H., 1975. Development of a selective medium for quantitative isolation of Fusarium oxysporum from natural soil. Rev. Plant Protect. Res. 8, 114-125.

Leslie, J.F., Summerell, B.A., 2006. The Fusarium Laboratory Manual. Blackwell Publishing IA, USA

Logrieco, A., Moretti, A., Castella, G., Kostecki, M., Golinski, P., Ritieni, A., Chelkowski, J., 1998. Beauvericin production by Fusarium species. Appl. Environ. Microbiol. 64, 3084-3088.

Marasas, W.F.O., Thiel, P.G., Rabie, C.J., Nelson, P.E., Toussoun, T.A., 1984. Moniliformin production in Fusarium section Liseola. Mycologia 78, 242-247.

Nelson, P.E., Toussoun, T.A., Marasas, W.F.O., 1983. Fusarium Species: An Illustrated Manual for Identification. Pennsylvania State University Press, PA, USA.

Nirenberg, H., OtDonnell, K., 1998. New Fusarium species and combinations within the Gibberella fujikuroi species complex. Mycologia 90, 434-458.

Palmero, D., de Cara, M., Iglesias, C., Moreno, M.M., Gonzalez, N., Tello, J.C., 2010a. First report of Fusarium proliferatum causing rot of garlic bulbs in Spain. Plant Dis. $94,277$.

Palmero, D., de Cara, M., Nosir, W., Iglesias, C., García, M., Woodward, S., Tello, J.C., 2010b. Pathogenicity and fusaric acid production by Fusarium proliferatum isolated from garlic in Spain. Phytopathology 100, S95

Palmero, D., de Cara, M., Cruz, A., González-Jaén, M.T., Tello, J.C., 2011a. Identification and mycotoxigenic potential of Fusarium proliferatum isolated from garlic in Albacete, Spain, and in vitro evaluation of temperature on radial mycelial growth. In: Abstracts of the International Congress of Postharvest Pathology, Lleida, Spain, p. 95.

Palmero, D., de Cara, M. Galvez, L, Tello, I.C, 2011b. Effect of pre-sowing treatment on postharvest garlic rot caused by Fusarium proliferatum. In: Abstracts of the International Congress of Postharvest Pathology, Lleida, Spain, p. 156.

Plattner, R.D., Nelson, P.E., 1994. Production of beauvericin by a strain of Fusarium proliferatum isolated from corn fodder for swine. Appl. Environ. Microbiol. 60, 3894-3896.

Querol, A., Barrio, E., Huerta, T., Ramón, D., 1992. Molecular monitoring of wine fermentations conducted by active dry yeast strains. Appl. Environ. Microbiol. $58,2948-2953$.

Ravi, N., Prasand, G., 2012. First report of Fusarium proliferatum causing rot of garlic bulbs (Allium sativum) in India. Plant Dis. 96, 290. 
Ritieni, A, Fogliano, V., Randazzo, G., Scarallo, A., Logrieco, A., Moretti, A., Mannina, L., Bottalico, A., 1995. Isolation and characterization of fusaproliferin. A new toxic metabolite from Fusarium proliferatum. Nat. Toxins 3, $17-20$.

Seefelder, A., Gossman, M., Humpf, H.U., 2002. Analysis of fumonisin B1 in Fusarium proliferatum-infected asparagus spears and garlic bulbs from Germany by liquid chromatography-electrospray ionization mass spectrometry. J. Agric. Food Chem. 50, 2778-2781.
Stankovic, S., Levic, J., Petrovic, T., Logrieco, A., Moretti, A., 2007. Pathogenicity and mycotoxin production by Fusarium proliferatum isolated from onion and garlic in Serbia. Plant Pathol. 118, 165-172.

Stepien, L., Koczyk, G., Waskiewicz, A., 2011. Genetic and phenotypic variation of Fusarium proliferatum isolates from different host species. J. Appl. Genet. 52 487-496.

Vares, L., Correa, E., Iglesias, C., Palmero, D., 2009. Influencia de la temperatura de termoterapia en el rendimiento del cultivo del ajo. Terralia 74, 30-34. 